\title{
Case Reports on Biochemistry and Analytical Biochemistry Journal- Open Access
}

\section{Monica Butnariu*}

Department of Chemistry and Biochemistry, Banat's University of Agricultural Sciences and Veterinary Medicine from Timisoara,300645, Calea Aradului 119, Timis, Romania

In the last year, the journal of Biochemistry and Analytical Biochemistry published articles written by experts in biochemistry and related fields for professors, researchers, students, managers, entrepreneurs and other groups of people interested in biochemistry and analytical biochemistry.

The journal objective's aim is to obtain results that highlight the creation of knowledge, competitiveness and strengthening the social dimension, continue a tradition of excellence and innovation in education and bio-analytical research.

Through a rich supply of topics offered by the journal of Biochemistry and Analytical Biochemistry it gives scientists the freedom to shape their own path through the transmission of scientific knowledge in biochemistry and related financings.

The objective of the journal is to promote theoretical and applied research in biochemistry and analytical biochemistry, in order to satisfy the academic community with current information on databases and related technologies with new knowledge, the growing theoretical and practical.

Currently, the journal is indexed in several international databases: Digital Object Identifier (DOI)-CrossRef, partial published articles is deposited in PubMed, 11 published articles get indexed with GALE. All published articles is deposited in Google Scholar, Scientific Commons, Index Copernicus and EBSCO.

The journal quality is continually improved by reviewing works, by using templates in accordance with international standards and the inclusion of the journal in other prestigious international databases.

Biochemistry and Analytical Biochemistry opens its pages to authors from different countries, encouraging publication of studies of international interest as well as case studies.

Without neglecting methodological aspect, the inter connection between different sciences provided by biochemistry and analytical biochemistry, the journal, has also the purpose to raise questions and provide solutions whenever individual disciplines such as biochemistry and various analytical methods used in this field facilitates the study of coherent research theme addressed, which cannot be totally understood using the tools of one single discipline research.

Biochemistry and Analytical Biochemistry encourages the publication of scientific results produced by using various research methodologies including case studies and comparative review, analysis of biochemical compounds, discussions, surveys, observation and other qualitative and quantitative research methods. Articles are chosen after a rigorous selection process.

Editorial board includes prestigious specialists in the field, from many reputed universities across the globe.

Their efforts, valuable experiences, and the future projects should be taken for an outline and scientific character. In their approach publishers wanted to reveal, for the informed and less informed public, all news and research in biochemistry and analytical biochemistry. "And how all this had to wear a name" were told "Biochemistry and Analytical Biochemistry".
*Corresponding author: Monica Butnariu, Department of Chemistry and Biochemistry, Banat's University of Agricultural Sciences and Veterinary Medicine from Timisoara, 300645, Calea Aradului 119, Timis, Romania, E-mail: monicabutnariu@yahoo.com

Received February 01, 2013; Accepted February 02, 2013; Published February 04, 2013

Citation: Butnariu M (2013) Case Reports on Biochemistry and Analytical Biochemistry Journal- Open Access. Biochem Anal Biochem 2:e135. doi:10.4172/2161-1009.1000e135

Copyright: (c) 2013 Butnariu M. This is an open-access article distributed under the terms of the Creative Commons Attribution License, which permits unrestricted use, distribution, and reproduction in any medium, provided the original author and source are credited. 